\title{
Dosimetria do Tl-201 em cintilografia de perfusão do
}

\author{
miocárdio
}

\author{
Tl-201 Heart Dosimetry in Miocardium Scintigraphic Image
}

\author{
J. M. Toledo ${ }^{1 *}$; B. M. Trindade' ${ }^{2}$ T. P. R. Campos ${ }^{3}$ \\ Departamento de Engenhria Nuclear, Universidade Federal de Minas Gerais, 31.270-901, Belo Horizonte - Minas \\ Gerais, Brasil
}

*janine.toledo@gmail.com

(Recebido em 13 de setembro de 2016; aceito em 7 de março de 2017)

\begin{abstract}
Este trabalho conduz ao estudo da cintilografia de perfusão miocárdica, e investigação da dosimetria espacial do TI-201 distribuído no miocárdio. Métodos e Resultados: A manipulação de dados radiológicos foi realizado a fim de criar um modelo computacional do voxel do coração. Um conjunto de imagens obtidas por angiotomografia da aorta torácica e abdominal forneceu informações anatômicas e funcionais para a modelagem do coração no código SISCODES. A distribuição homogênea do TI-201 foi assumido no músculo cardíaco. Simulações do transporte de partículas através dos voxels e a interação com os tecidos do coração foram realizadas através do MCNP - Código Monte Carlo. A distribuição espacial de dose no modelo de coração é apresentado, bem como o histograma dose versus volume no músculo cardíaco. Para validação do estudo foi utilizado um modelo analítico. Conclusão: A presente ferramenta computacional gerou distribuição de dose espacial na cintilografia de perfusão do miocárdio. Especialmente, a dosimetria realizada elucida a dose transmitida no músculo cardíaco por unidade de atividade injetada de Tl-201, o que pode contribuir para futuras investigações de efeitos determinísticos no coração.

Palavras-chave: dosimetria, tálio 201, miocárdio.
\end{abstract}

Background: This paper conducts a recalling in myocardial perfusion imaging (MPI) followed by a spatial dosimetric investigation of the ${ }^{201} \mathrm{Tl}$ distributed at the myocardium. Methods and Results: Radiological data manipulation was prepared and a computational heart voxelized model was assembled. A set of images from abdominal aorta and angiotomography of the thorax was set up providing anatomic and functional information for heart modeling in SISCODES code. A homogeneous distribution of Tl-201 was assumed into the heart wall. MCNP - Monte Carlo Code was used to provide the photon transport into the heart model taking into consideration the interactions into the tissues. The spatial dose distribution and histogram dose versus volume are presented. An analytical alternative model was addressed to the data validation. Conclusion: The presently developed tools can produce spatial dose distribution in MPI. Especially, the dosimetry performed elucidates imparted dose in the myocardial muscle per unit of injected Tl-201 activity, which can contribute to future deterministic effect investigations.

Keywords: dosimetry, thallium 201, myocardial

\section{INTRODUCTION}

Myocardial perfusion imaging (MPI) becomes an important tool in diagnosis and monitoring patients with cardiovascular disease (CVD).[1-3] On MPIs, a radiopharmaceutical is injected into a peripheral vein and is subsequently captured by myocyte cells of the heart. The uptake radioisotope emits radiation that is converted into a scintigraphic image, generated through a cardiac CT. The images are obtained in two physical patient stages: rest and stress with blood flow increased into the heart. Radiopharmaceuticals accumulate to the heart muscle in function of the flow of blood, which is analyzed according to a decrease in the intensity of radioisotope uptake in some part of the heart muscle. When this uptake is transient, coronary ischemia is pointed out; when it is persistent, fibrosis is the situation. Thus, myocardial perfusion imaging allows the physicians to search the viable areas, separating them from unviable ones. In this case, this procedure is called myocardial viability. [4] 
The first MPI was performed in 1944 by Carr, based on Cesium-131, Potassium-43 was used in 1973 by Zaret et al. [4-6] It was possible to visualize the myocardial ischemia on induced stress. Analogue of potassium, thallium-201 (Tl-201) was presented in 1974. Such radionuclide has been applied for 30 years satisfactorily. In the $90^{\text {th }}$, innovative chemical compounds target with technetium-99m (Tc-99m) holding new biological features were presented to assess MPI. Thus, a variety of perfusion compounds can be applied to image the blood flow distribution in the myocardium. Also, an exact value of blood flow at myocardium cannot be estimated with CT images and Single Photon Emission Tomography (SPECT); however, it is performed with Positron Emission Tomography - PET. [4]

The most important clinical application of MPI on stress is the evaluation of ischemic heart. The Tl-201 or Tc-99m targeted compounds are used in this diagnosis. Generally, the correlation between the MPIs in stress condition and angiography findings of the coronary artery with contrast is good. There is sufficient evidence that the finding in MPIs with stress reflects the hemodynamic and functional stenosis of the coronary artery, providing important prognostic information. [5] Regarding the images in stress, 25\% were generated with Tl-201 and 75\% with Tc-99m target agents. SPECT was often used in more than $90 \%$ of the studies. [5]

Thallium-201 chloride, as a flow tracer, once injected intravenously, is distributed to almost all body tissues (except brain, due to their failure to transpose the blood-brain barrier) in function of the blood flow in locus and accumulates mainly in the cardiac muscle, kidneys, liver, intestines and skeletal muscles. [7] As observed in the study, quantitative analysis of a Tl-201 washout and redistribution parameters, as presented by the authors, allows discriminating between coronary artery pathology with non-early infarction in myocardium (based on the T1-201 redistribution) and with an early infarction of myocardium (considering non-T1-201 redistribution). [39]

Despite the long-term application of MPI, spatial dose distribution at the myocardium during this procedure is poorly understood, due to the complex of radiopharmaceutical dynamics in such anatomic dynamic structure. Since ${ }^{201} \mathrm{Tl}$ is a good tracer for MPI, it has been applied in clinic for more than 20 years. [40] The present paper conducts a heart dosimetric investigation in MPI with Tl-201 radiopharmaceutical in order to elucidate the myocardium spatial imparted dose distribution. This investigation is justified by the possible induced-radiation deterministic effects, especially in the microvasculature of the heart muscles and the modulation of matrix metalloproteinases and citocines. [35]

\section{MATERIALS AND METHODS}

\section{Heart model for perfusion image}

A set of sixty normal heart CT sections of an adult's chest was used. Each section reproduced a $2 \mathrm{~mm}$ layer. Thus, 355 axial CT sections, including heart and mediastinum were included. [8]

SISCODES code converted this set of images into a voxelized tissue model. [9-12] The chemical composition and mass density were previously digitalized into SISCODES database. Also, the nuclear data, from ICRU-46, was introduced in the data bank [13]. Each tissue was represented by a color.

SOFT-RT software developed in-house by NRI group, provided the 3D-visualization of the model. $[15,16]$ It is made by OpenGL routines, which can render 3D views of the SISCODE models.

Each tissue and organ was identified previously. Thus, dosimetric protocol can be simulated. Later, information of the radioactive sources is incorporated. Each voxel from myocardial muscle received a distributed source of Tl-201. Thus the activity per unit of mass was homogeneous at all heart muscle, which is a simplification of the complex Tl-201 dynamic at the heart. The gamma spectrum from Tl-201 was specified from literature (Decay Data from ENSDF or Medical Internal Radiation Dose- MIRD) [21] Thallium - Tl-201 is provided by circular accelerators and presents $72.912 \mathrm{~h}$ of half-life. In their process of electronic capture decay, the X-ray radiation of 9.98 (16.9\%, Hg L $\left.\alpha_{1}\right), 68.89$ (27.0\%, Hg K $\alpha_{2}$ ), 70.81 (46.0\%, Hg K $\alpha_{1}$ ), 80.25 (10.5\%, Hg K $\beta_{1}$ ), 
plus a gamma radiation of $167.43 \mathrm{keV}(10 \%)$ and $135.34 \mathrm{keV}(2.5 \%)$ are emitted predominantly. [17]

Thus, the data are transferred to an MCNP file. The file was treated in the MCNP5 code [14]. The Monte Carlo (MC) method can be used to simulate theoretically a stochastic process, as the particle interaction with bone and soft tissue, and is particularly interesting for solving complex problems of nuclear transport that cannot be evaluated by codes based on deterministic formulations. In MC particle transmission, each of many particles emitted by Tl-201 is followed throughout its interaction until escape or absorption events, among others, finalized the transport. The simulations account for scattering effects near the chest and the lungs, which play an important role in case of Tl-201. Thus, the output was transferred to SISCODES code. The isodose curves of the spatial dose distribution were generated. Dose versus volume histograms was prepared.

\section{Imparted dose evaluation}

The imparted dose on each voxel of the heart can be obtained multiplying the MCNP simulation result $(r)$, in Gy per transition, by patient's injected activity $(A)$ in Bq, and by the integral of the percentage of the heart uptake over time, defined by $p(t)$, namely time integral factor. Therefore, the dose is expressed as:

$$
D=r A \int_{+i}^{t f} p
$$

The function $p(t)$ is influenced by two separated mechanisms: the Tl-201 radioactive decay and the thallium radiopharmaceutical clinic dynamics. Both mechanisms have exponential behavior, so, $p(t)$ can be expressed as a biexponential function [18]:

$$
p(t)=C 0 e^{\left(\frac{-\ln (2) t}{C 1}\right)}+C 2 e^{\left(\frac{-\ln (2) t}{C 3}\right)}
$$

where $C 1$ and $C 3$ are constants relatives to half-life of the radiopharmaceutical dynamics and the radioactive decay, and $C O$ and $C 2$ are the weights of each exponential term.

\section{Validation}

Due to the difficulty in taking in vivo dose's measurements at the cardiac muscle directly, validations with experimental results could not be performed. Therefore, let us compare imparted doses from the computational method and from an analytical method of calculation. Thus the average dose rate of the MCNP voxel's model shall be compared to a value evaluated analytically based on a simplified model of the heart.

For a uniformly distributed gamma-emitting isotope, the dose rate $D R$ at the center of a sphere volume like-heart filled to a radionuclide is

$$
D R=C . \Gamma \cdot S
$$

in which $C$ is the concentration of the radioisotope in unit of Bq. $\mathrm{cm}^{-3}, \Gamma$ is the specific gammaray emission, and $S$ the geometric factor in unit of meter. [18]

$$
S=\frac{4 \pi\left(1-e^{-\mu r}\right)}{}
$$


in which $\mu$ is the linear energy absorption coefficient and $r$ the sphere's radius. [19]

The $\Gamma$ factor relates activity and exposure rate at a specific radionuclide. This factor $\Gamma$ is defined as

$$
\Gamma_{\delta}=\frac{l^{2}}{=}\left(\frac{d k_{\text {air }}}{-}\right)
$$

in which $\left(\mathrm{d} K_{\text {air }} / \mathrm{d} t\right)_{\delta}$ represents the air kerma rate from photons of energy greater than $\delta$, at a distance $l$ taken from a point source of $A$ activity. The $\Gamma_{\delta}$ has SI units of $\mathrm{J} \mathrm{m}^{2} \mathrm{~kg}^{-1}$, which becomes $\mathrm{Gy} \mathrm{m}^{2} \mathrm{~s}^{-1} \mathrm{~Bq}^{-1}$, after conversion. Replacing air kerma in Eq.5, $\Gamma$ can be written as

$$
\Gamma_{\delta}=\frac{1}{*} \sum(\stackrel{\mu k}{)}) p_{i} E_{i}
$$

in which $\rho$ is the mass density, $p_{i}$ is the probability of photon emission and $E_{l i}$ the photon energy for the $i^{\text {th }}$ emitting on the Tl-201 decaying, summed by all photon emitting. $\Gamma_{\delta}$ was calculated based on the air mass energy-transfer coefficients and the photon emission yield in the decay of the Tl-201 radionuclide. The subscript $\delta$ implies that only photons with energy greater than 10 $\mathrm{keV}$ are included in the calculation.

\section{RESULTS}

\section{Heart model}

The tissues from the voxel model of the heart were previously inserted in the SISCODES database. Such data table has already been published [22]. Figure 1 shows, respectively, the cardiac tomography imaging and the heart voxel model, in two and three-dimensional views. In this Figure 1, some sections of the voxel model of the heart are presented at XY-plane from the SISCODES interface. Also, 3D-dimensional images were depicted from SOFT-RT on three distinct perspectives.
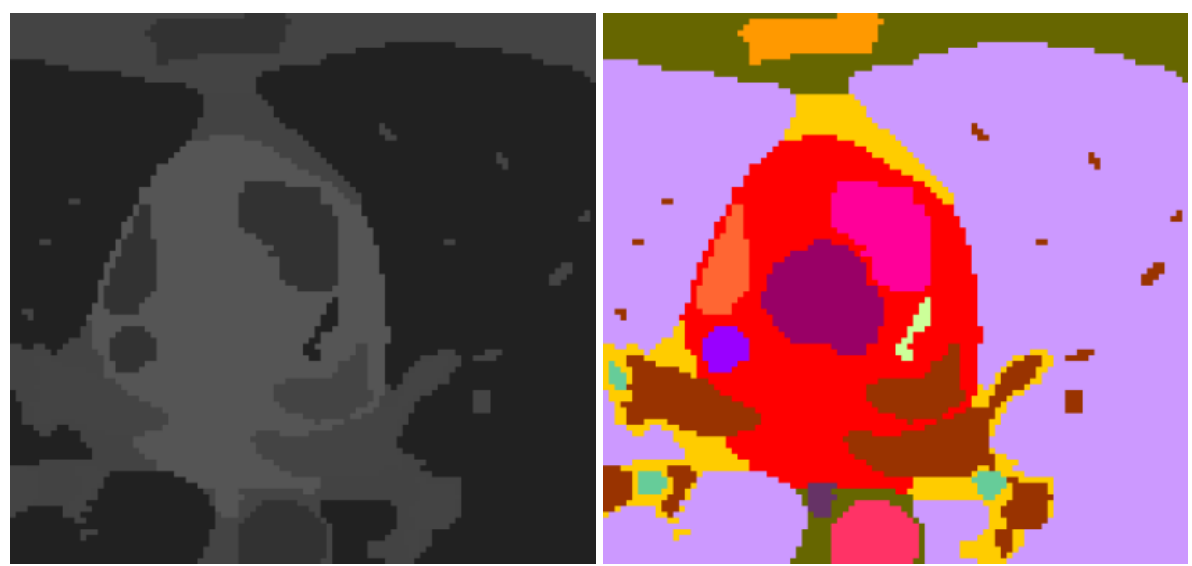

Figure 1: The cardiac tomography imaging and the heart voxel model

Figure 2 depicts three sections of the heart voxel model generated by the MCNP5, after transferring data of the model to the MCNP code, in which simulations were performed. As a result of these simulations, the isodose curves in the voxel model of the heart are presented, as well as the dose versus a volume histogram of the heart. 

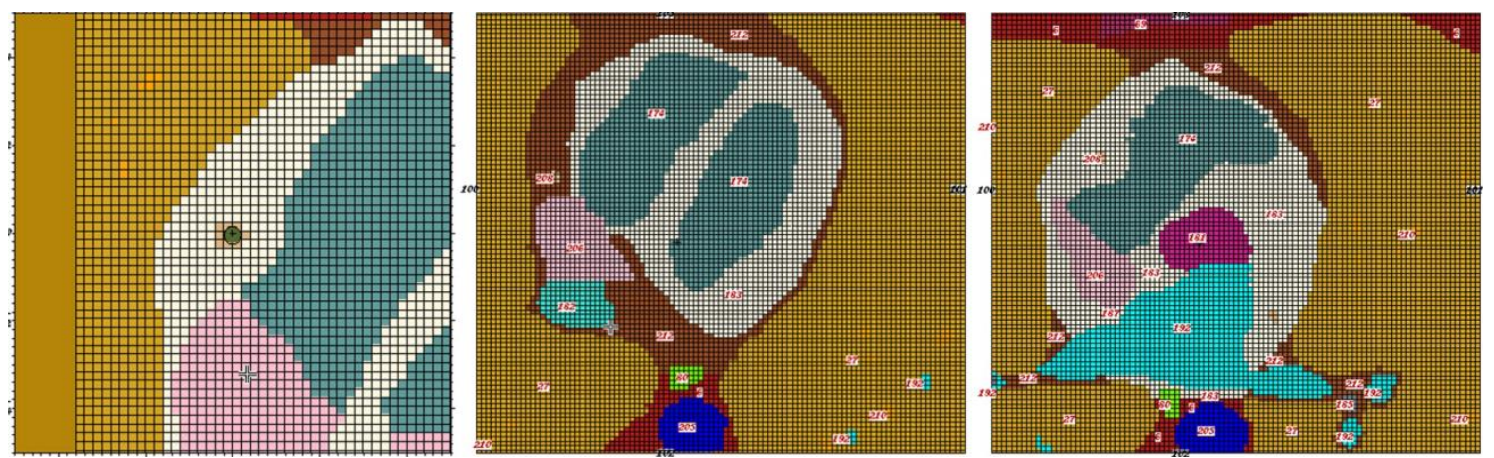

Figure 2: Sections of the voxel model generated by MCNP5, after transferring data of the heart model to the MCNP code.

\section{Imparted dose}

Figure 3 presents the percentage isodose areas in the heart sections, following by the value distribution. The percentage of absorbed dose represented by isodose curves is based on a maximum value, which in this case was $2.11 \times 10^{-11}$ Gy per radionuclide emitting. All values are normalized to the maximum value. The look-up table - LUT, as well as the percentile ranges assigned to each color, was chosen to generate images similar to those obtained from myocardial imaging on SPECT.

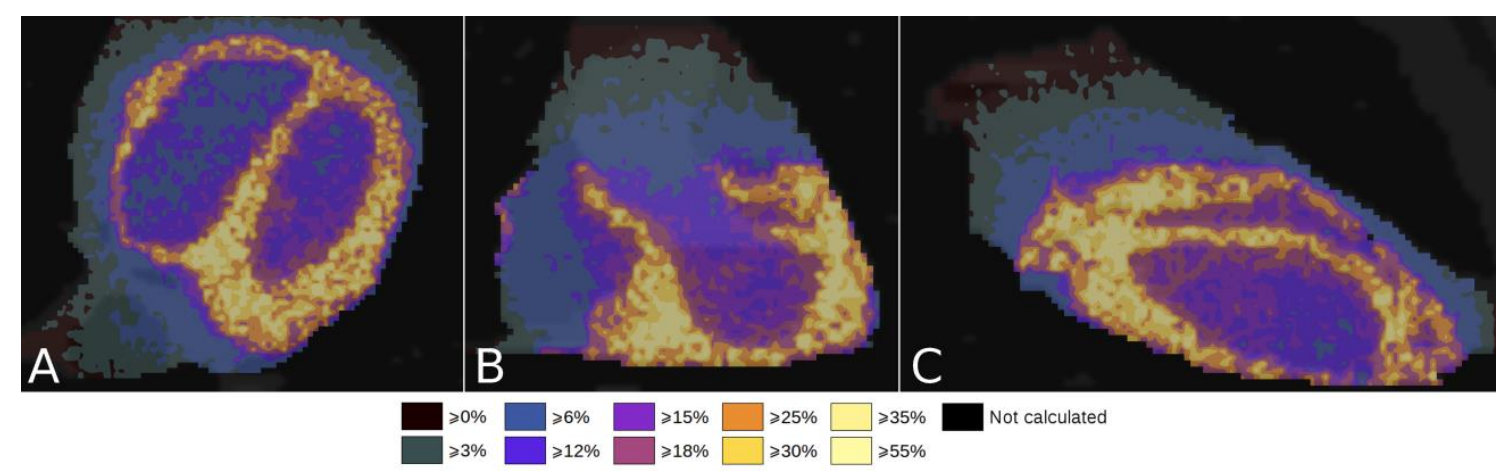

Figure 3: The percentage isodose areas on the heart sections, following by the value distribution.

Figure 4 present the same images after applying a blur filter and converting to grayscale with contrast enhance. In order to obtain imparted dose, the Eq. 1 was applied. The $C 0, C 1, C 2$ and $C 3$ in Eq.2 were obtained by non-linear fit to experimental data on the heart uptake as a function of time, presented by Bradley-Moore et al. [23]. These data are shown in Table 1.

The values obtained were: $C O=3.32053 ; C 1=17637.7 ; C 2=0.479739$; and $C 3=252497$. Therefore the dose imparted on this procedure was evaluated as follows:

$$
D=r A \frac{1}{100} \int_{t_{i}}^{t_{f}} 3.32053 \cdot e^{\left(\frac{-\ln (2) \cdot t}{17637.7}\right)}+0.479739 \cdot e^{\left(\frac{-\ln (2) \cdot t}{252497}\right)} d t
$$

The term $100^{-1}$ exists because experimental data are expressed in percentile of total injected activity. The integral limits $t_{i}$ and $\mathrm{t}_{\mathrm{f}}$ taken are $t_{i}=0 \mathrm{~s}$, at the moment of Tl-201 injection, and $t_{f}=$ $2624832 \mathrm{~s}$ corresponds to ten Tl-201 half-lives. The integral result was $259121.36 \mathrm{~s}$.

One can see from Fig. 3 that the isodose curves are so dispersed on the heart muscle that it cannot be easily interpreted. Therefore, a histogram dose versus volume may be helpful. 


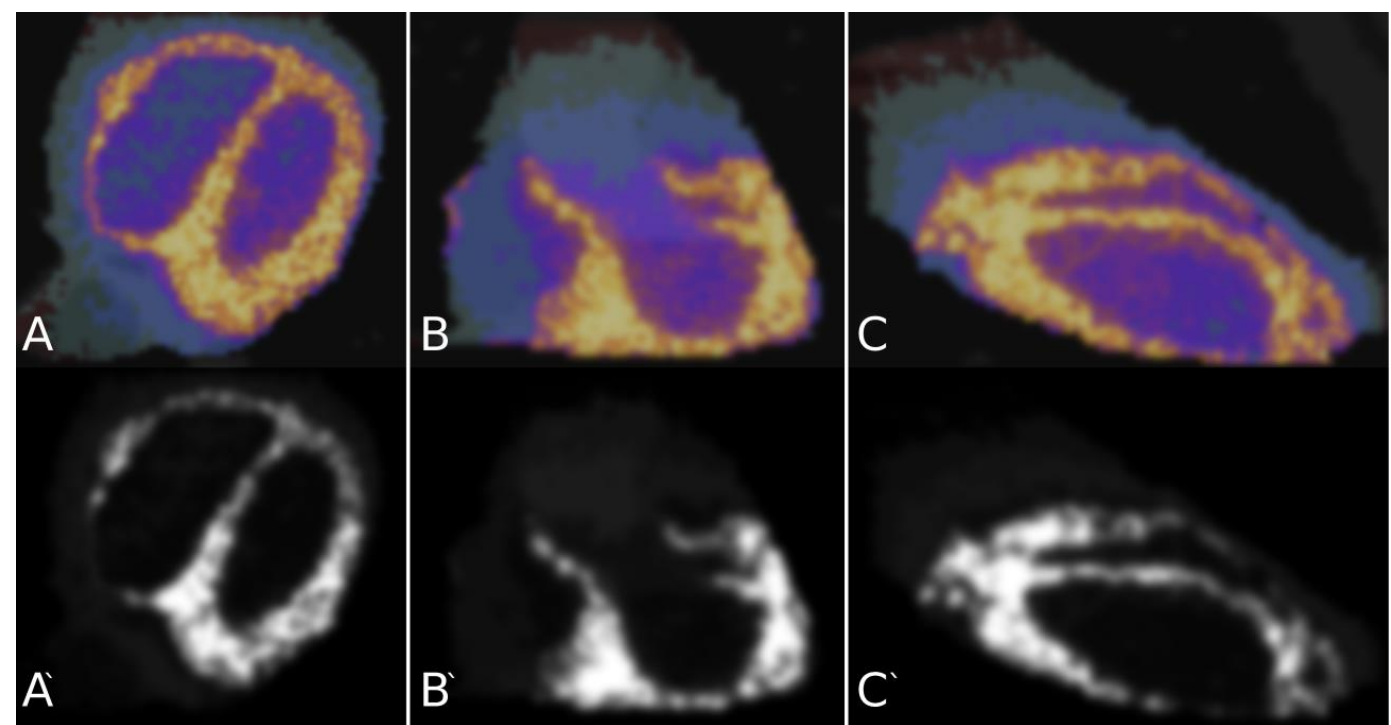

Figure4: Images after applying a blur filter and converting to grayscale with contrast enhance

Table 1 - Experimental data from Bradley-Moore et al. [23] of the thallium heart uptake as a function of time.

\begin{tabular}{cc}
\hline Time after thallium & Heart uptake \\
injection (s) & (\% of injected activity) \\
\hline 600 & 3.65 \\
1500 & 3.70 \\
6300 & 3.00 \\
7800 & 2.96 \\
72000 & 0.58 \\
\hline 230400 & 0.27 \\
\hline 604800 & 0.08 \\
\hline
\end{tabular}

Figure 5 represents the histogram that shows the relationship between absorbed doses to the volume percentage. Considering an injection of $148 \mathrm{MBq}$ (4 mCi) of Tl-201, almost 100\% of heart volume received, at least, $0.1 \mathrm{mGy}$, about $90 \%$ of the heart muscle and $75 \%$ of the coronary artery received $0.4 \mathrm{mGy}$ or more, about $70 \%$ of the heart muscle and $55 \%$ of the coronary artery received $0.6 \mathrm{mGy}$ or more, and less than $10 \%$ of the heart muscle and $5 \%$ of the coronary artery received doses over $1 \mathrm{mGy}$. The maximum punctual absorbed dose in the heart muscle was 2.64 mGy and on coronary artery was $1.23 \mathrm{mGy}$. The heart muscle received a greater dose when compared to dose received by the coronary artery. 


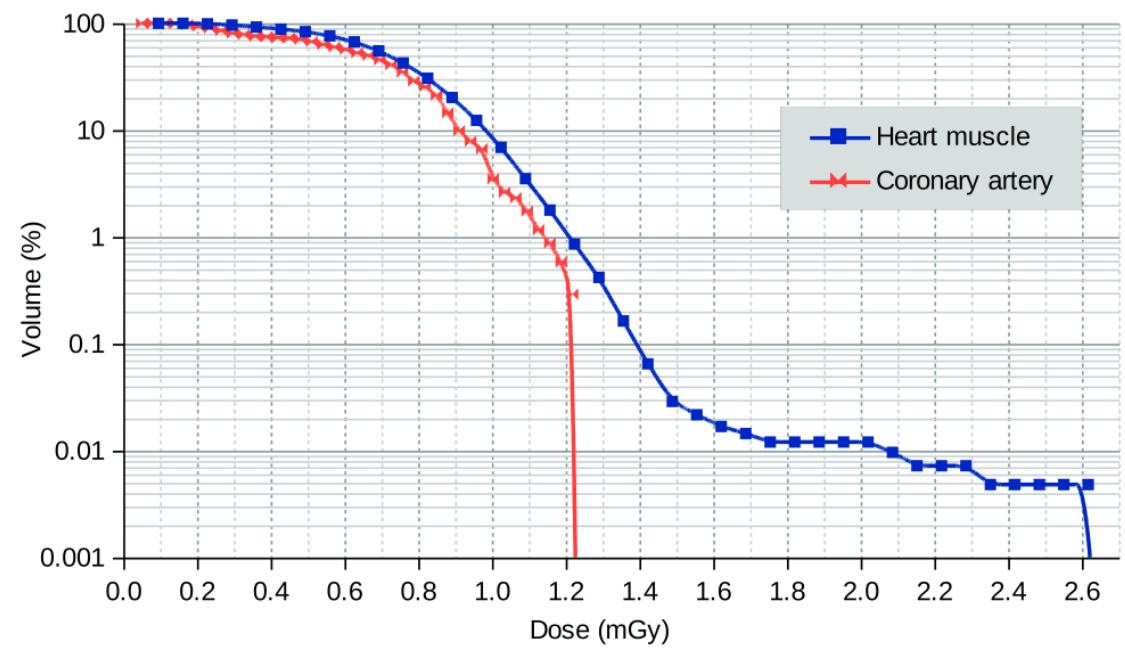

Figure 5: The histogram that shows the relationship between absorbed doses to the volume percentage.

\section{Validation}

A tissue-filled sphere of $4.5 \mathrm{~cm}$ radius and a mass of $0.4 \mathrm{~kg}$ represented the heart, with the thallium radionuclide distributed homogeneously. The $(\mu / \rho)$ is $0.0280 \mathrm{~cm}^{2} \cdot \mathrm{g}^{-1}$ at $70 \mathrm{keV}$ (gamma with maximum emitting percentage of 37\%), heart muscle mass density $\rho$ was adopted 1.05 g.cm 3. From Eq.6, the specific gamma-ray $\Gamma$ constant for ${ }^{201} \mathrm{Tl}$ was $4.7 \mathrm{R} \cdot \mathrm{h}^{-1} \cdot \mathrm{mCi}^{-1}$ at $1 \mathrm{~cm}$. Thus, the mass energy-absorption coefficient of the heart muscle, $\mu$, was $0.0294 \mathrm{~cm}^{-1}$; and, the $S$ factor (Eq. 4) was $52.97 \mathrm{~cm}$.

Therefore, from Eq. 3, the dose rate DR was evaluated multiplying: $4.7 \mathrm{R} \cdot \mathrm{cm}^{2} \cdot \mathrm{h}^{-1} \cdot \mathrm{mCi}{ }^{-1}$, $52.97 \mathrm{~cm}$ and $0.0003877 \mathrm{mCi} . \mathrm{cm}^{-3}$ that means DR of $0.09657 \mathrm{R}^{-1} \mathrm{~h}^{-1}$. In order to convert DR unit to Gy, the relation R/Gy equal to 0.00877 was applied. So, DR was $0.0008469 \mathrm{~Gy} \cdot \mathrm{h}^{-1}$.

Imparted dose D can be found multiplying DR by the integral time factor, as shown in Eq.1. Assuming the heart uptake of $3.7 \%$ of the injected activity of $148 \mathrm{MBq}$, equivalent to $4 \mathrm{mCi}, \mathrm{D}$ can be found, multiplying $0.0008469 \mathrm{~Gy} \cdot \mathrm{h}^{-1}$ to $2591.2136 \mathrm{~s}$ and converting factor of h.3600 $3 \mathrm{o}^{-1} \mathrm{~s}^{-1}$, providing $0.6095 \mathrm{mGy}$ of imparted dose.

Thus, the dose obtained from analytical calculus was $0.6095 \mathrm{mGy}$. From histogram, the average dose from the heart voxel model was $0.670 \mathrm{mGy}$. Those values are in the same order of magnitude and differentiate into $9 \%$.

\section{DISCUSSION}

The myocardial uptake of thallium-201 is rapid at rest individuals, with about $90 \%$ of the uptake occurring in the first pass. Its condition is reproduced by the time integral factor assumed in our calculations. During exercise, new uptake condition, which means new parameters C0 up to $\mathrm{C} 4$, shall be investigated. Tl-201 uses active transport mechanisms by the sodium-potassium pump and passive diffusion dependent on the transmembrane electric potential gradient. Rest or exercise condition changes the uptake and eliminating functions. [4] When compared to the agents labeled with technetium-99m, the extraction of thallium-201 myocardial correlates more linearly with the increase in the coronary flow. The present studies can be reproduced to Tc-99m MIB changing the kinetics function.

Traditionally used in myocardial perfusion imaging thallium-201 has recently been employed less as a result of its unfavourable energy profile and of its long physical half-life that limits the injected concentration, with advantages for agents labeled with technetium- $99 \mathrm{~m}$. However, it is still used in ischemic heart disease due to the long experience, especially in Brazil. In some centers, this agent is of first choice. [3] Thus the present study is relevant not only to present imparted dose in the heart but due to the presentation of a new methodology to dose calculation, which may be followed to investigate Tc-99m and F-18 radiopharmaceuticals. 
The MIRD committees of the Society of Nuclear Medicine, coin MIRD schema [20, 38], developed a widely used method for internal dose evaluation. The International Commission on Radiological Protection (ICRP) adopted such methodology following similar reference data [21]. The MIRD schema adopted a 70-kg adult anthropomorphic model and performed dosimetry by multiplying absorption and transmitting factors for each organ and radionuclide type, which is proportional to the uptake function according to the established target and source. MIRDOSE [24], DOSCAL [25], MABDOS [26] are software that helps to apply MIRD method in nuclear medicine. [28] MIRD provides an average equivalent dose in the target organ. The method does not address the maximum dose. Herein, spatial dose distribution can be achieved by the voxels model simulation discriminating dose in a specific part of the organ such as the coronary artery, as an example. Such improvement can contribute to better specify the deterministic effects of radiation in the myocardium muscle, especially in relation to the modulation of MMPs.

Atkins et al. [29] and Krahwinkel et al. [30] provided the maximum Tl-201 uptake in human organs, presenting $0.15-3 \%$ of the administered activity. However, Gupta et al [30] and Hosain [31] demonstrated high values for testicular uptake at $14 \mathrm{~h}$ of $0.8 \%-1 \%$. These high doses to tests resulted in some concern for younger over Tl-201 application. In the near future, the present modeling can be applied to test and validate such findings.

Contaminants such as $\mathrm{Tl}-200, \mathrm{Tl}-202$, and $\mathrm{Pb}-203$ radionuclides may bring concerns in relation to image; however, such contaminants contributed very little for the imparted dose to the heart. Indeed, such contaminants will contribute $1.0 \%$ for Tl-200 and Tl-202 and $0.1 \%$ for Pb203 to the imparted dose. So, such contaminants were not included in the present results.

The present calculations provided the imparted dose in units of Gy. The effective dose in units of $\mathrm{Sv}$ was not evaluated. In this case, weighting factors shall be used. MIRD scheme presents the effective dose in Sv and many authors follow it. From MIRD schema, heart wall presented $0.23 ; 0.28$ and $0.25 \mathrm{mSv}$ by ICRP [32], RIDIC [33] and Thomas et al. [34]

The present study does not address the average organ effective dose, but the spatial absorbed dose distribution at the myocardium. Therefore it shall contribute to elucidate dose at this tissue and relation to deterministic effects. Herein, the dose was evaluated at the myocardium due to the source activity in this organ. In the near future, the dose contribution from other organs will be added to the study.

According to Einstein et al., [35] a high cumulative effective dose to various individuals undergoing myocardium perfusion image was revealed, mainly for those undergoing repeating tests. More than $30 \%$ of the individuals received $100 \mathrm{mSv}$ as the cumulative effective dose. MPI alone, the median cumulative effective dose was $28.9 \mathrm{mSv}$ (IQR, 27.9-55.6 mSv; mean [range], 44.6 [6.5-406.9] mSv). Those high cumulative dose values shall bring concerns to the stochastic risk. The present methodology does not deal with risk assessment but the deals with absorbed dose in myocardium voxels. Indeed, the method provides a spatially discriminated absorbed dose in the myocardium, which can be correlated to an average effective dose at the organ.

Heart disease induced by radiation is a potential deterministic effect of ionizing radiation at the heart exposition with doses provided by scattering radiation from external radiation beam therapy. [36] The clinical effects may be present many years after irradiation. Their symptoms are pericardial and myocardial fibrosis, accelerated atherosclerosis, injury to cardiac valves, and conduction abnormalities. [36]

MPI may not induce a potential radiation-induced effects due to its very small imparted dose; however, ionizing radiation in a small dose is involved in the reduction of microscopic myocardial capillary density, increasing the activity of matrix metalloproteinase's (MMPs) in heart, interstitial collagen degradation, and endothelial dysfunction mediated by of TGF- may be present. [37,38] After spatial dose discrimination at the myocardium, further investigation about radiobiological effects shall be requested.

\section{CONCLUSION}

As a conclusion, the present computational tool is capable of generating spatial dose distribution at myocardial perfusion imaging protocol. Further studies involving differential 
uptakes from patient's images shall be made to obtain dosimetric data for each clinical situation. Especially, the performed dosimetry elucidates spatial imparted dose distribution in the myocardial muscle per unit of injected Tl-201 activity.

\section{ACKNOWLEDGMENTS}

The authors acknowledge the National Council of Technological and Scientific Development (CNPq), process n. 550661/2007-7 and n. 471173/2007-0 and Universal-2009 by financial aid and the help of a scholarship from "Coordenação de Aperfeiçoamento de Nivel Superior" (CAPES). We also acknowledge "Fundação de Apoio a Pesquisa em Minas Gerais" (FAPEMIG) by the financial support of the Universal 2011 to the NRI research group.

\section{BIBLIOGRAPHIC REFERENCES}

1. Braunwald, Eugene. Tratado de medicina cardiovascular. 6.ed. São Paulo: roca, 2006. v.1 e v. 2

2. Galt JR. Germano G. Advances in instrumentation for cardiac SPECT, In: DePuey EG, Garcia EV, Berman DS, eds, cardiac_SPECT_imaging. New York: Raven Press, 1995:91-102.

3. Follansbee WP. Alternatives to leg exercise in the evaluation of patients with coronary artery disease: functional and pharmacologic stress modalities. In: Myron CG (ed). Cardiac Nuclear Medicine. New York: McGraw-Hill; 1997:193-235.

4. Case JA. Attenuation correction and scatter correction of myocardial perfusion SPECT images. In: Zaret BL, Beller GA, eds. Clinical Nuclear Xardiology: state of the art and future directions, $4^{\text {th }}$ ed. Philadelphia: Elsevier-Mosby, 2010: 111-120.

5. Taillefer R, E. Depuey G, Udelson J E., et al. Comparative Diagnostic Accuracy of Tl-201 and Tc - 99m Sestamibi SPECT Imaging (Perfusion and ECG-gated SPECT in Detecting Coronary Artery Disease in Women. J Am Coll Cardiol 1997; 29:69 -77.

6. Heller GV, Bateman TM, Johnson LL, et al. Clinical value of attenuation correction in stress-only Tc-99m sestamibi SPECT imaging, Journal of Nuclear Cardiology. 2004 May/June; 11: 273-81.

7. Saha BG. Fundamentals of nuclear pharmacy. 5th ed. New York: springer-verlag, 2004. (4) 4662.

8. Digital Imaging and Communications in Medicine (DICOM) Part 1: Introduction and Overview. National Electrical Manufacturers Association. 2006.

9. Trindade BM, Campos TPR. Stochastic method-based computational system for neutron/photon dosimetry applied to radiotherapy and radiology, Radiol Bras. 2011 Mar/Abr; 44(2):109-116, doi:10.1590/S0100-39842011000200011.

10. Trindade BM. Desenvolvimento de Sistema Computacional para Dosimetria em Radioterapia por Nêutrons e Fótons Baseado em Método Estocástico - Siscodes. Adviser: Campos TPR. Universidade Federal de Minas Gerais, Belo Horizonte, 2004; 102p.

11. Trindade BM, Christóvão MT, Trindade DFM, Falcão PL, Campos TPR. Comparative dosimetry of prostate brachytherapy with I-125 and Pd-103 seeds via SISCODES/MCNP, Radiol Bras, 2012, 45(5): 267-272, doi:10.1590/S0100-39842012000500007.

12. NRI-Núcleo de Radiações Ionizantes, UFMG. Available at <http://dgp.cnpq.br/buscaoperacional/detalhegrupo.jsp?grupo=0333309JFCSTQ6>. Accessed on: September 15, 2010.

13. ICRU Report 44: Tissue substitutes in radiation dosimetry and measurement, 1989.

14. MCNP - X-5 Monte Carlo Team. A general Monte Carlo N-particle transport code manual, version 5. Los Alamos, NM: Los Alamos National Laboratory, 2003.

15. Fonseca TCF. Desenvolvimento de um Sistema Computacional para Planejamento Radioterápico da Técnica IMRT Aplicado ao Código MCNP com Interface Gráfica 3D de Modelos de Voxels. [dissertation]. Belo Horizonte (MG): Universidade Federal de Minas Gerais em Belo Horizonte; 2009.

16. Fonseca TCF, Campos TPR. Software for simulating IMRT protocol. Proceedings of the International Nuclear Atlantic Conference; 2009, September 27 to october 2; Rio de Janeiro, BR. ABEN 2009; 1-7.

17. Firestone RB, Ekström LP. LBNL Isotopes Project - LUNDS Universitet. Available at <http://ie.lbl.gov/toi/>. Accessed on: October 4, 2010.

18. Cember H. Introduction to health physics. New York: Pergamon Press; 1983. 861p. 
19. Hubbell JH. Photon Cross Sections: Attenuation Coefficients and Energy Absorption Coefficient from $10 \mathrm{keV}$ to $100 \mathrm{GeV}$. Washington DC: NBS Publication; 1969. 85p.

20. Loevinger R. The MIRD perspective. in: Adelstein S. Kassis A, Burt R, eds. Dosimetry of Administered Radionuclides. Washington, DC: American College of Nuclear Physicians, United States Department of Energy, 1989: 29-43

21. International Commission on Radiological Protection. Radiation Dose to Patients from Radiopharmaceuticals at ICRP publication no. 53. Oxford, UK: International Commission on Radiological Protection, 1983.

22. Fonseca KR , Trindade, BM, Campos, TPR, development of a voxel model of the heart for dosimetry, Artificial Organs, Vol 35, Issue 5, May 2011, 459-464.Bradley-Moore PR, Lebowitz E, Greene MW, Atkins HL, Ansari AN. Thallium-201 for medical use, part 2: biological behavior. J Nucl Med. 1977; 18(2): 133-140.

23. Stabin MG. MIRDOSE: personal computer software for internal dose assessment in nuclear medicine. J NucI Med. 1996 Mar; 37(3):538-46.

24. Sgouros G, Bigler R, Zanzonico P. DOSCAL: a tumor-incorporating mean absorbed dose calculation program [abstract]. J Nucl Med. 1988; 29(suppl):874.

25. Johnson TIC, McClure D, McCourt S. MABDOSE: part 1: Characterization of a general purpose dose estimation code. Med Phys. 1999; 26: 1389-95.

26. Zanzonico PB, Internal radionuclide radiation dosimetry: a review of basic concepts and recent developments. J Nucl Med. 2000 Fev; 41(2): 297-308.

27. Stabin MG, Radiopharmaceuticals for Nuclear Cardiology: Radiation Dosimetry, Uncertainties, and Risk. J Nucl Med. 2008 Sep; 49(9): 1555-63, doi:10.2967/jnumed.108.052241.

28. Atkins HL, Budinger TF, Lebowitz E, et al. Thallium-201 for medical use, part 3: human distribution and physical imaging properties. J Nucl Med. 1977 Feb; 18(2): 133-40.

29. Gupta SM, Herrera N, Spencer RP, et al. Testicular-scrotal content of Tl-201 and Ga-67 after intravenous administration. Int J Nucl Med Biol. 1981; 8: 211-213, doi:10.1016/00470740(81)90079-6.

30. Hosain P, Hosain F. Revision of gonadal radiation dose to man from thallium-201. In: Proceedings of the Third International Radiopharmaceutical Dosimetry Symposium. Oak Ridge, TN: Oak Ridge Associated Universities. 1981; 333-345.

31. International Commission on Radiological Protection. Radiation Dose to Patients from Radiopharmaceuticals. New York, NY: Pergamon Press. 1988; 38: ICRP Publication 53. ISSN 046-6453. ISBN 978-0-7020-3450-3.

32. Stabin MG, Stubbs JB, Toohey RE. Radiation Dose Estimates for Radiopharmaceuticals. Washington, DC: U.S. Nuclear Regulatory Commission, U.S. Department of Energy, U.S. Department of Health and Human Services. 1996; NUREG/CR-6345.

33. Thomas SR, Stabin MG, Castronovo FP. Radiation-absorbed dose from 201Tl-thallous chloride. J Nucl Med. 2005; 46: 502-508.

34. Einstein AJ, Weiner SD, Bernheim A, Kulon M, Bokhari S, Johnson LL, Moses JW, Balter S., Multiple Testing, Cumulative Radiation Dose, and Clinical Indications in Patients Undergoing Myocardial Perfusion Imaging, JAMA. 2010 Nov; 304(19):2137-44, doi:10.1001/jama.2010.1664.

35. Boerma M, Hauer-Jensen M. Preclinical Research into Basic Mechanisms of Radiation-Induced Heart. Cardiology Research and Practice. 2010 Sep; (2011), doi:10.4061/2011/858262.

36. M. Scharpfenecker, J. J. C. M. Kruse, D. Sprong, N. S. Russell, P. ten Dijke, and F. A. Stewart. Ionizing radiation shifts the PAI-1/ID-1 balance and activates notch signaling in endothelial cells. International Journal of Radiation Oncology Biology Physics. 2009 Feb; 73(2): 506-513.

37. Bolch WE. MIRD Pamphlet No. 21: A Generalized Schema for Radiopharmaceutical Dosimetry Standardization of Nomenclature. J Nucl Med. 2009 Mar; 50(3):477-84.

38. Murray DB, Gardner JD, Brower GL, Janicki JS. Effects of nonselective endothelin-1 receptor antagonism on cardiac mast cell-mediated ventricular remodeling in rats. Radiat Res. 2008 Sep; 170(3): 275-283, doi:10.1667/RR1093.1.

39. Hor G, Sebening H, Sauer E, Dressler J, Lutilsky L, Wagner-Manslau C, Bofilias I, Wolf I, Pabst $\mathrm{H} \mathrm{W} .{ }^{201} \mathrm{Tl}$ - redistribution analysis in early and delayed myocardial scintigrams of patients with coronary heart disease. Eur J Nucl Med. 1979 Oct; 4(5): 343-350, doi:10.1007/BF00263302.

40. Hesse B, Tagil K, Cuocolo A, Anagnostopoulos C, Bardiés M, Bax J, et al. EANM/ESC procedural guidelines for myocardial perfusion imaging in nuclear cardiology. Eur $\mathbf{J}$ Nucl Med Mol Imaging. 2005 Jul; 32(7): 855-97; PMID: 15909197. 